\title{
LIFE AND WORK OF OLIVER HEAVISIDE (MAY 18, 1850-FEBRUARY 3, 1925)
}

\begin{abstract}
" $\mathrm{F}^{\mathrm{s}}$ ROM time to time there live among us men of genius whose creative work is inadequately recognised by their contemporaries but who, later, are found to have rendered a service of the highest value to the advancement of Science--such a man was Oliver Heaviside."*

During the afternoon and evening of May 18, a commemorative meeting in honour of Oliver Heaviside was held at the Institution of Electrical Engineers under the chairmanship of the president of the Institution, Prof. E. B. Moullin, supported by the president of the Royal Society, Sir Robert Robinson. This was followed, on May 20, at the Sorbonne in Paris, by a similar meeting organised by the Société des Radioélectriciens and conducted under the chair. manship of Prince Louis de Broglie, permanent secretary of the Paris Academy of Sciences.

The afternoon session of the London meeting was devoted to the presentation of an appreciation of "Heaviside, the Man" by. Sir George Lee, formerly engineer-in-chief of the Post Office, and to supporting tributes by Sir Robert Robinson, Sir Edward Appleton, Dr. M. J. H. Ponte (president of the Société Française des Electriciens), Sir Archibald Gill, Dr. O. E. Buckley (president of the Bell Telephone Laboratories of America), Prof. Harold Jeffreys, Sir Edmund Whittaker and Dr. G. F. C. Searle, who, from varied points of view, testified to the wide mathematical, physical and engineering significance of Heaviside's work. The presence and contribution of Dr. Searle, now eighty-five years of age, were much appreciated by all present because of his close and extended friendship with Heaviside. They met first in 1892; one of the few real friendships of Heaviside's secluded life resulted, and Dr. and Mrs. Searle did much to assist him during the difficult domestic circumstances which existed during the last ten years of his life.
\end{abstract}

The evening session was devoted to the presentation of abstracts of four papers (available in advance) dealing with various aspects of Heaviside's work. One, by Prof. B. van der Pol, was concerned with the operational calculus devised by Heaviside for the solution of the problems of telegraph and telephone line transmission which were his main preoccupation. Another, by Prof. Willis Jackson, dealt with his contribution to electromagnetic theory, notably with his reformulation of Mexwell's equations and his establishment of the theory of line transmission on Maxwell's basis. A third, by Dr. W. G. Radley, discussed the impact of Heaviside's work on the subsequent development of telecommunications; while a fourth, by Mr. H. J. Josephs, consisted of a reconstruction of some of Heaviside's very extensive unpublished notes.

The meeting was made the more interesting by an exhibition which included a pictorial survey of various stages of Heaviside's life, the diploma of doctorate honoris causa presented to him by the University of Gottingen, a selection from his unpub. lished manuscripts and a number of letters, including one from Lord Rayleigh, who, writing as secretary of the Royal Society to inform Heaviside of the

" Foreword, J. Inst. Elect. Eng., April 1950. acceptance of one of his papers, remarked, "Both our referees, while reporting favourably on what they could understand, complain of the exceeding stiffness of your paper. One says it is the most difficult he has ever tried to read. Do you think you can do anything by illustrations or further explanations to meet this? As it is I should fear that no-one will take advantage of your work."

The programme of the Paris meeting comprised an opening address by Prince Louis de Broglie, followed by contributions from M. Ed. Picault, inspectorgeneral of the French Post Office, Prof. P. Humbert, of the University of Montpellier, M. S. Colombo, senior scientist of the Centre National de la Recherche Scientifique, M. P. M. Prache, president of the Telecommunications Section of the Société Française des Électriciens, M. L. Bouthillon, of the École Poly. technique, Sir Edward Appleton, representing the Royal Society, and Prof. Willis Jackson, representing the Institution of Electrical Engineers.

There were also on exhibition a series of letters between Heaviside and M. J. F. T. Bethenod, the eminent French industrial inventor and scientist, who in a letter dated December 7, 1917, paid the following tribute to Heaviside : "The dream of my life has been to sign my name to works like yours because, à tout ou à raison, I imagined myself to be capable of it when I was 20 years old. Fate has decided otherwise, for fifteen years I have had to devote myself to the study of industrial questions and I fear that after the war there will be no more time."

Oliver Heaviside was born and lived, to the age of eighteen, at 55 King Street (now Plender Street), London, W.1. His father was a wood engraver, and his uncle, on his mother's side, the famous inventor and telegraph pioneer, Sir Charles Wheatstone. The latter was no doubt responsible for his initial employment at Fredericia in Denmark in 1868 as telegraph operator with the Danish-Norwegian-English Telegraph Co., one of the first telegraphic organisations to use Sir Charles's apparatus. The first AngloDanish cable was laid between Newcastle upon Tyne and Fredericia in 1868, and when, in 1870, this cable was taken over by the Great Northern Telegraph Co., Heaviside was transferred to Newcastle as chief operator. His notebooks, now in the possession of the Institution of Electrical Engineers, give details of his early experimental work and of the problems which soon began to exercise his mind. On July 5, 1872, he published his first paper entitled "Comparing Electromotive Forces" in the English Mecharic, and thus began the spate of publications which, brought together in the two volumes of his "Electrical Papers" and the three volumes of his "Electromagnetic Theory", cover more than 2,500 pages of close type and contain about $1 \frac{1}{2}$ million words or their mathe. matical equivalent. His early papers were of an essentially prectical character. His notes show, how. ever, that he was seeking mathematical means of clarifying the phenomena he observed, and that he soon became aware that their explanation would require a more comprehensive theory of line trans. mission than was afforded by the submarine cable 
solution formulated by Kelvin in 1855, which took account only of line resistance and capacitance and ignored-though quite justifiably for the signalling conditions with which Kelvin was then concernedself-inductance.

By 1874 he had decided that his employment with the Great Northern Telegraph Co. was interfering too seriously with his theoretical work, and towards the end of that year he resigned and returned to live with his parents in London. The family moved to Paignton in 1889 ; then, following the death of his parents, Oliver lived in Newton Abbot from 1897 until 1909, when he was offered a home by Miss Way, sister-in-law to his brother Charles, and lived at Homefield, Torquay, until his death in 1925: From 1874 onwards he worked in seclusion, and during the later years of his life under conditions of considerable austerity.

Oliver Heaviside's first major analytical contribution, made in 1876, consisted of his extension of Kelvin's solution to include the effect of selfinductance and of his recognition of the fact that signals were transmitted along the line with a velocity determined dominantly by the product of the capacitance and inductance per unit length, and which, contrary to the existing belief, was independent of the line length. It was not until 1881, however, that he linked these phenomena with Maxwell's theory of electromagnetic wave propagation. Between 1881 and 1885 he devoted himself to a discussion of this theory, and of vector algebra, and to a representation of Maxwell's equations in the vector algebra form in terms of the electric and magnetic field intensities in which they are now normally stated. He did not elaim to have added anything to Maxwell's theory as such, and in respect of vector analysis gave full credit to the priority of Willard Gibbs ; but his achievement in putting this theory into a form more suitable for use in the solution of practical problems was considerable, as was recognized by Hertz, who came to a similar formulation of it a few years later. In the course of his analysis, Heaviside independently derived Poynting's flux of energy theorem within a few months of Poynting himself, and in more general form, but in all subsequent references spoke of it as the Poynting flux.

Having satisfied himself that his line equations formulated in 1876 conformed, subject to certain limitations, with Maxwell, he proceeded to develop a comprehensive theory of line propagation, on which all the subsequent developments in telephone line communication have been based.

To Heaviside's great disappointment, his advocacy of the beneficial effect of artificially increasing the line inductance and his proposals for doing so were not acceptable to Sir William Preece, then engineerin-chief of the British Post Office. They had no practical outcome until, in a paper read to the American Institute of Electrical Engineers in 1899, Prof. M. I. Pupin, of Columbia University, described experiments which showed convincingly that a line of high uniformly distributed inductance could be substantially imitated by one of lower self-inductance in which coils were located at appropriate regular intervals along its length-one of the alternative suggestions of Heaviside himself.

In 1901 the British Post Office began experiments on 'loading coils', as they were called later, and in the following year a complete circuit in the first London-Birmingham telephone cable was loaded experimentally. The first British long-distance circuits to be loaded for practical purposes were in the Liverpool-Warrington cable in 1903, and the procedure became a standard practice in main underground cables immediately after the Finst World War.

Heaviside had no better fortune with the mathematicians than with the engineers. The operational calculus which he developed for dealing with the propagation of disturbances along lines evoked very severe criticism, a consequence of the unsystematic way in which he treated these problems and of his lack of concern for rigour in the mathematical sense. He wrote: "Those who may prefer a more formal and logically-arranged treatment may seek it elsewhere and find it if they can; or else go and do it themselves"; and "I do not write for rigourists (although their attention would be delightful) but for a wider circle of readers who have fewer prejudices, although their mathematical knowledge may be to that of the rigourists as a straw to a haystack". This type of statement-and many more potent ones might be quoted-did not, of course, contribute to the removal of misunderstanding ; but suffice it now to say that his methods were later proved to be fully justified, and that Sir Edmund Whittaker was able to write in 1929 : "Looking back on the controversy after thirty years, we should now place the Operational Calculus with Poincarés discovery of Automorphic Functions and Ricci's discovery of the Tensor Calculus as the three most important mathematical advances of the last quarter of the nineteenth century. Applications, extensions and justifications of it constitute a considerable part of the mathematical activity of to-day."

During the period 1889-1902, Heaviside wrote a number of papers dealing with the electromagnetic effects associated with electrically charged bodies in steady and accelerated motion; In particular, in 1889, he stated, within half a page, the relation normally attributed to Lorentz, who derived it three years later, for the force experienced by a charge in steady motion in a magnetic field. J. J. Thomson had previously given the force as one-half the correct value, and it would seem that Heaviside sensed the correct relation intuitively from Thomson's analysis, but did not trouble to record that he had done so.

In 1902 he contributed an article on "The Theory of Electric Telegraphy" to the tenth edition of the "Encyclopædia Britannica". In the course of this article he stated that Hertzian waves travelling round the earth might "accommodate themselves to the surface of the sea in the same way as waves follow wires", and that there might "possibly be a sufficiently conducting layer in the upper air. Then the guidance will be by the sea on the one side and the upper layer on the other." It was fitting that the first experimental demonstration of the truth of this remarkable and far-reaching prediction came through the work of another famous Englishman, Sir Edward Appleton, and that Heaviside's name, joined with that of Kennelly, should be associated with the layer.

It is also of interest to note the extent to which Heaviside's mind was prepared for the recent developments in microwave technique as revealed by his emphasis on the care to be exercised in using his transmission-line theory at frequencies for which the wave-length is of the same order as the conductor separation, and by a limited treatment in 1888 of wave propagation inside a cylindrical conducting tube-what is now called a cylindrical wave-guido- 
some nine years before Rayleigh's more comprehensive analysis.

It remains to mention his advocacy, dating back to 1882 , of the rationalization of units, a topic which is receiving much attention at the present time in connexion with discussions of the M.K.S. system, and also his contributions to the terminology of electrical engineering. The number of terms which originated with him is remarkable. Thus, he was responsible for the introduction of the words resistance, conductance, inductance, permittivity, impedance, admittance, reluctance, permeance, distortion and electrets; while several other terms which did not originate with him owe much to him for their now general application.

The first volume of Heaviside's great work, "Electro-Magnetic Theory", was published in 1893 and the second in 1899. In the preface of the first edition of the third volume, Heaviside stated that it had been his intention to publish the third volume in 1904 and a fourth in 1910. But circumstances had not been favourable; his third volume did not appear until 1912, while the fourth and concluding volume was never published.

The portion of the unpublished notes discussed by Mr. Josephs was presumably to form part of this fourth volume. Whether the manuscript was ever completed is not known, though Heaviside was engaged in negotiations for its publication at intervals during the period 1917-22. It is a great misfortune that many of these notes, now in the possession of the Institution of Electrical Engineers, are in very bad condition, but Mr. Josephs has nevertheless been able to piece together substantial portions of the proposed volume. The notes contain some remarkable mathematical work; they show Heaviside to have been much exercised to the end with ideas on the electrical theory of matter and with the statistical nature of physical laws, and record his continued striving towards the development of a unified theory of the electromagnetic and gravitational fields, a topic on which he made his first publication in 1893 .

Heaviside's life was in some respects a great tragedy, but he emerges from it a man of tremendous intellectual stature; an extreme individualist, who in one of his letters says: "My results, however imperfect they may be, have at least the recommendation of having been worked out in a mind uncontaminated by the prejudices engeridered by prior knowledge acquired at second-hand"-a man who scorned honour when it was offered in his lifetime, but to whom it may now be given in the abundance he deserves.

He was elected a fellow of the Royal Society in 1891 ; a Civil List pension was awarded to him in 1896 ; in 1905 the University of Göttingen conferred on him the degree of Ph.D.; he was elected an honorary member of the Institution of Electrical Engineers in 1908 and of the American Institute of Electrical Engineers in 1918, and when in 1921 the Institution of Electrical Engineers founded the Faraday Medal in memory and honour of that great scientific worker, they selected Heaviside as the first recipient. The task of presenting the Medal to Heaviside fell to J. S. Highfield, then president, who wrote: "It is impossible to give any adequate account of one who so despised what most men desire; but when I left him I felt that he was content, that he respected the Institution, and that it had pleased and made happy one of its famous men".

WIIMIS JACKSON

\section{NEW CYTOTOXIC AGENTS WITH TUMOUR-INHIBITORY ACTIVITY}

By DR. F. L. ROSE, O.B.E., and DR. J. A. HENDRY

Imperial Chemical Industries, Ltd., Research Laboratories, Hexagon House, Manchester, 9

and DR. A. L. WALPOLE

Imperial Chemical Industries, Ltd., Biological Laboratories, Wilmslow

$T_{\text {and }}^{T}$ HE observations of our colleagues Templeman and Sexton ${ }^{1}$ upon the effect of carbamic esters on the growth and morphology of cereal seedlings, those of Haddow and Sexton ${ }^{2}$ upon the influence of selected members on animal tumours, and the findings of Haddow, Paterson and co-workers ${ }^{3}$ that the ethyl ester (urethane) has a therapeutic action on certain forms of leukæmia in man, prompted us to attempt to elucidate the chemical basis of the several effects produced by these compounds. To this end we prepared some thirty simple homologues of urethane and examined them for growth-inhibitory activity against the Walker carcinoma 256 in rats. Of these, only bis-and tris-carbethoxyamine even approached urethane in activity, a finding which has been amply substantiated in similar investigations by Haddow (private communication) and by the more recent work of Skipper and his associates 4,5 , who have studied the toxicology and the action upon experimental leukæmia of a similar series of carbamates.

At that time we envisaged the possibility that urethane interferes with cellular proliferation by virtue of its capacity to react with amino-groups; the fact that potassium cyanate had been claimed to have anti-mitotic action lent support to this idea. In consequence, we examined a wide range of substances capable of analogous interaction with these groups to yield not only ureas, as does urethane, but also other functional derivatives. Most of these were monofunctional in that each molecule carried only one reactive group such as halogeno, cyano, thiocyano, cyanate, isocyanate, keto, aldehydo, thiol or alkylthiol. A minority were bi- or tri-functional, this being achieved, for example, by including an alkylene chain between two reactive groups as in compounds of the type EtO.CO.NH( $\left.\mathrm{CH}_{2}\right)_{n} \mathrm{NH}$.CO.OEt, so that the nature and disposition of the reactive groups was not unlike that in the 'nitrogen mustards'. Altogether, rather more than a hundred such derivatives were prepared and examined before significant growth-restraining activity on the Walker tumour was encountered, and the purpose of this com. munication is to record those initial observations, together with later developments which may have a fundamental bearing on the chemistry of cell division.

The active substances fall into three classes. In the chronological order of the discovery of their effect these are: (a) polymethylolamides, (b) bisepoxides, (c) structures carrying two or three ethylene imine residues*. We were led in the first place to examine substances of type (a) because of their known application in paper and textile technology where, as described by our colleague Mr. J. G. Evans, their usefulness is probably associated with poly-alkylating function, a feature that is clearly of significance in the 'sulphur' and 'nitrogen mustards', and because

- Since this paper was prepared, workers at and associated with the Sloan-Kettering Research Institute, New York, have described the use of ethylene imine derivatives against certain experimental cancers (Arch. Biochem., 28, (2), 319, 321 (1950). 